\title{
Hydrological feasibility of gravity diversion of the west flowing Nethravathi in Karnataka
}

\author{
Mysooru R Yadupathi Putty ${ }^{1, *}$, N M Thipperudrappa ${ }^{2}$ and P N Chandramouli ${ }^{1}$ \\ ${ }^{1}$ The National Institute of Engineering, Mysore 570 008, India. \\ ${ }^{2}$ Siddaganga Institute of Technology, Tumkur 572 103, India. \\ *Corresponding author.e-mail: puttyyadupathi@gmail.com
}

The concept of collecting surface runoff on the slopes in canals cut across the western slopes of the Western Ghats, in order to divert part of a flow in the west flowing rivers to the east by gravity, is being promoted in Karnataka. This paper presents a study of the hydrological feasibility of such canals, termed 'garland canals' and claimed to be an environmental friendly alternative to the conventional technologies for inter-basin transfer of water, by their promoters. The paper presents a methodology for disaggregating normal annual rainfall into 15-min magnitudes and its application for simulating surface runoff, using a knowledge of infiltration rates on the slopes. The study has been carried out considering a part of a garland canal proposed for diverting the river Netravathi in the state. The results from the study reveal that significant amounts of flow can be collected in the proposed canal only if streams are also tapped and that because of the arrangements necessary for the purpose, garland canals cannot be considered a means superior to the conventional methods for diverting west flowing rivers.

\section{Introduction}

Interlinking of rivers has been among the most discussed technological issues in the country during the last 10-12 years. Even though most of the components of the 'National Water Grid' planned by the National Water Development Authority (NWDA) remain unrealistic for various reasons and seem to be forgotten already, those links in the peninsular component, which are intended to divert west flowing waters to the east, particularly in Karnataka, continue to be discussed and investigated. Amongst these, the Netravathi diversion scheme has been the most prominent, since the idea has been making rounds in the state since the early 1990s. Sri G S Paramasivaiya, a retired Chief Engineer of the Water Resources Department of Karnataka, has suggested a scheme for diverting water by gravity, by means of what are called 'garland canals' (Paramasivaiya 2000). The concept of 'gravity diversion' consists of tapping surface runoff that occurs as sheet flow on the western slopes of the Western Ghat mountain ranges by means of a contour canal, constructed at such an elevation that it collects sufficient quantities of water, and diverting the canal to the east at a location where the topography is suitable for it to be taken around the escarpment to reach the other side. There are a few portions of the Western Ghats in Karnataka where this type of topography is found. Although wrecked by many controversies pertaining to the technical aspects, this scheme is being talked about since a long time. One important highlight of the scheme, as claimed by its promoters, is that it is environmentally viable, in that it does not involve construction of large dams and does not need tunneling and lifting water. It

Keywords. Inter-basin transfers; sheet-flow interception; garland canals; hydrological feasibility; rainfall disaggregation; conventional technologies. 
is further claimed that it does not envisage to tap streams, since only the sheet flow is to be collected and diverted (Paramasivaiya 2000).

At least on paper, this idea of garland canals looks attractive. However, investigations in the Western Ghat areas (Putty and Prasad 2000) have established that runoff processes in the region are different from those in the plains and that surface runoff on slopes, in the form of sheet flow, forms only a very small part of stream flow. This raises serious doubts concerning the availability of sufficient amounts of flow for being collected in the canals and diverted. This means that hydrological feasibility of diversion by canals must be considered, before studying the technical details of the scheme. The present work has been taken up in order to look into this aspect of garland canals, the proposals concerning which have been taken seriously by the authorities. In fact, the scheme pertaining to the Netravathi basin, planned by a committee of experts constituted by the Govt. of Karnataka, has been referred to ISRO for being studied for its technical feasibility. Since the feasibility report has not yet been finalised, the proposals continue to be talked about and quoted often. The present study has been carried out with the intention of investigating whether the said canal in the Netravati basin is able to divert the proposed amount of water and serve the purpose it is planned for.

\section{The study area and the scheme of garland canals}

Netravathi is the largest of the west flowing rivers in Karnataka. It drains an area of $3180 \mathrm{~km}^{2}$ in to the Arabian Sea and carries an annual discharge of about 12,000 $\mathrm{Mm}^{3}$ (410 TMC), excluding diversions, which are all only on a micro scale. A major portion of the basin lies in the Western Ghat region, which is characterized by steep slopes with thick and largely evergreen forests, deep and highly well drained soils. The catchment spreads across the western part of Karnataka between the latitudes $12^{\circ} 30^{\prime}$ and $13^{\circ} 15^{\prime}$, and covers parts of the districts of Kodagu, Hasana, Dakshina Kannada, Udupi and Chikkamagaluru (figure 1). The scheme for diverting Netravathi (figure 2) proposed by Paramasivaiya (2000) consists of a canal flowing north, starting from a point near the boundary of the catchment bordering the basin of Kaveri, an east flowing river. It intercepts parts of the catchment of Kumaradhara, which is the largest tributary of Netravathi, and that of the primary segment of Netravathi itself and is proposed to end at a point on the boundary of the basin bordering the catchment of Bhadra, another east flowing river. The canal runs parallel to the Western Ghat ridges to a length of $234 \mathrm{~km}$, draining an area of $182 \mathrm{~km}^{2}$. An attempt is made here to estimate the

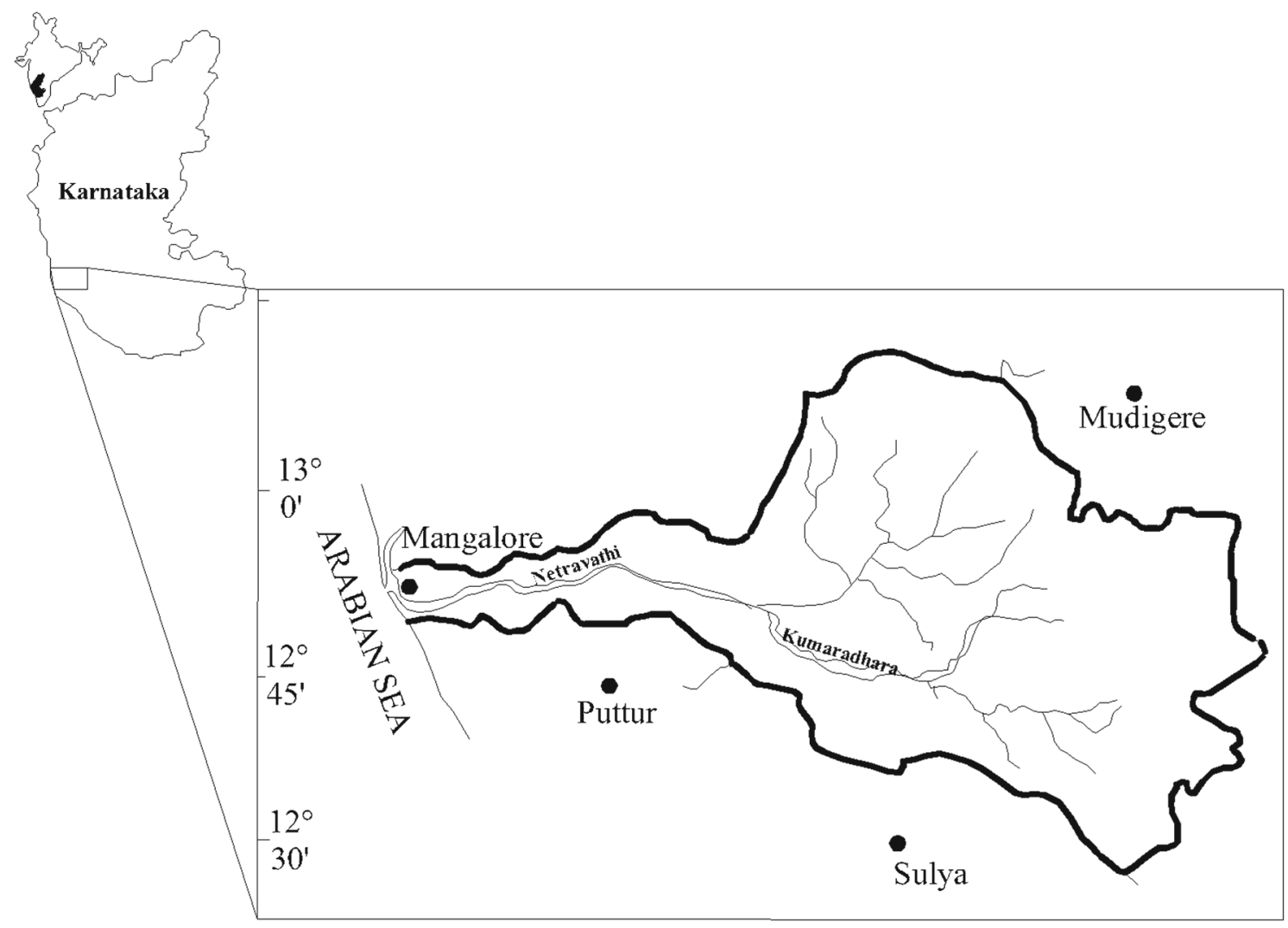

Figure 1. The basin of river Netravathi. 
amount of sheet flow on the surface that may be intercepted by the garland canal. The work has been accomplished by estimating runoff in a typical stretch of $70 \mathrm{~km}$ of the canal (figure 2).

The region of the Western Ghats where the canal is to run is made up of four types of topographic formations: (i) the steep Appalachian slopes in between valleys, with dense vegetation; (ii) the rounded crests covered with thick pasture and rocky outcrops in small parts; (iii) the steep and narrow valleys covered by a local variety of evergreen forests called 'Shola' (see Plates 1 and 2), and (iv) the nearly flat valley portions, riparian to the streams, part of which often get saturated

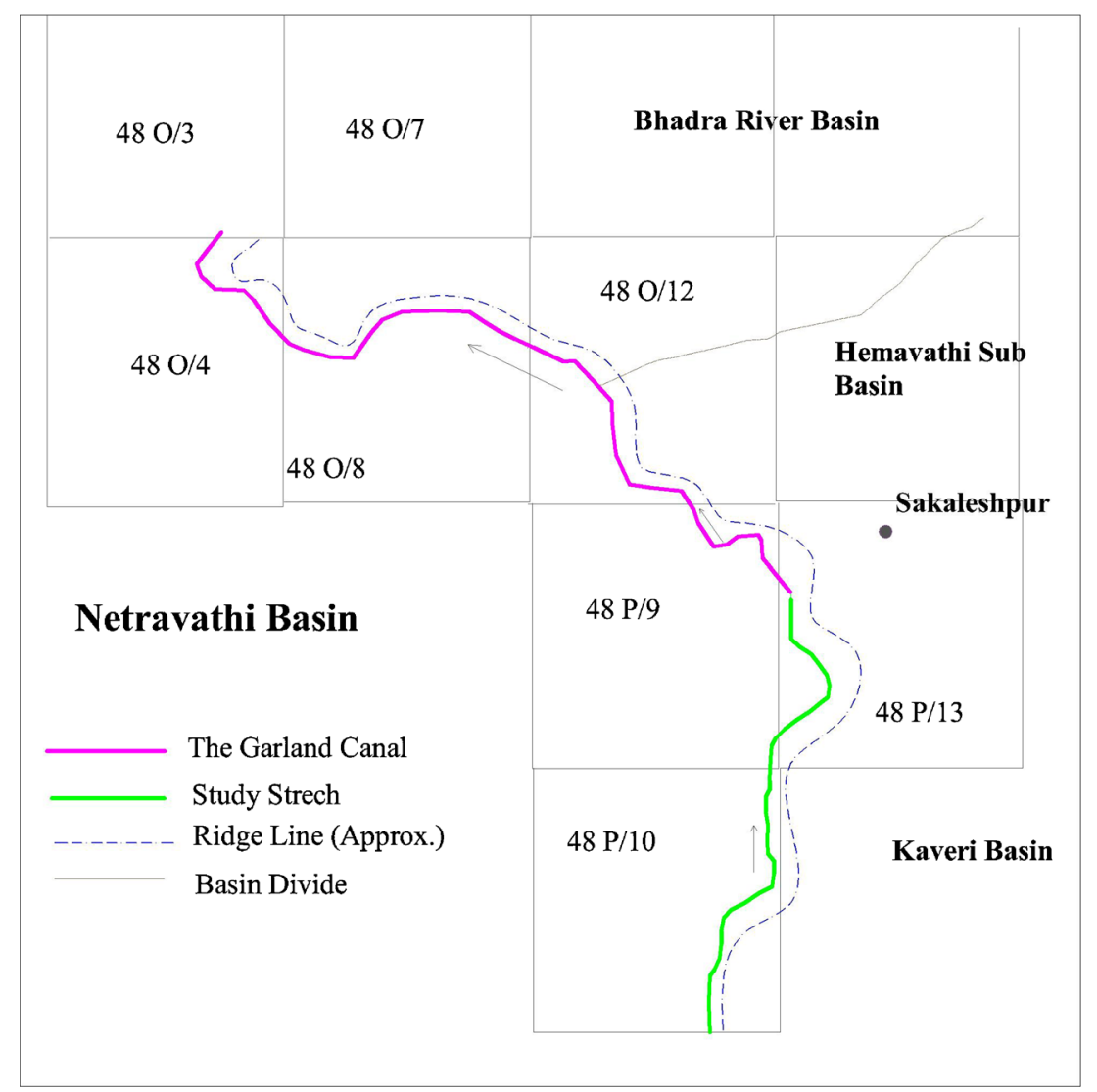

Figure 2. The proposed location of the garland canal and the study stretch.

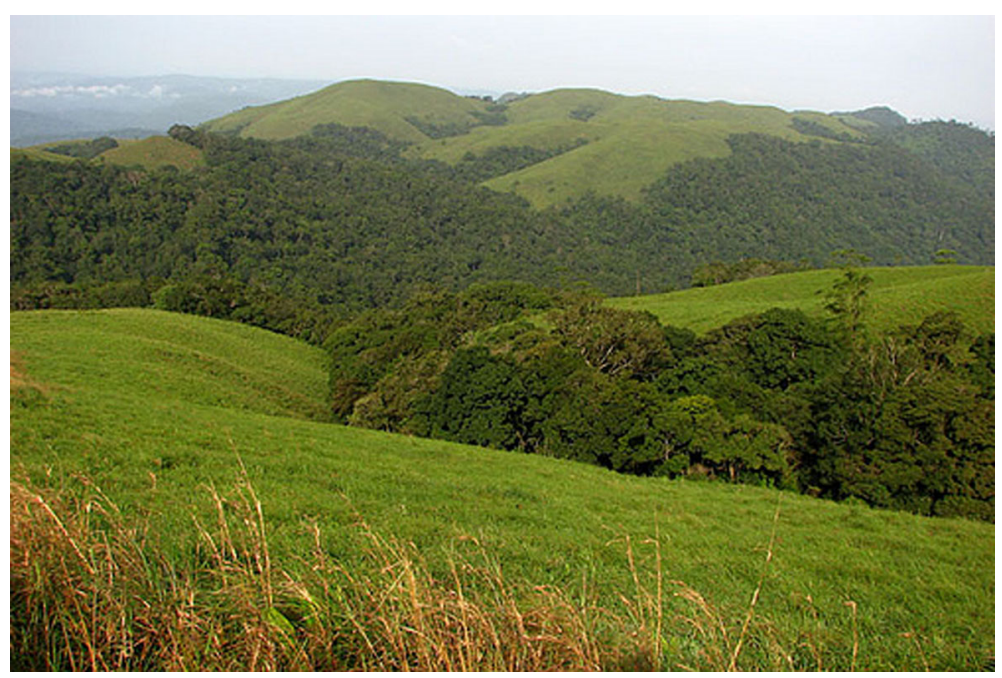

Plate 1. Typical landscape of the area through which the garland canal passes near the head waters. 


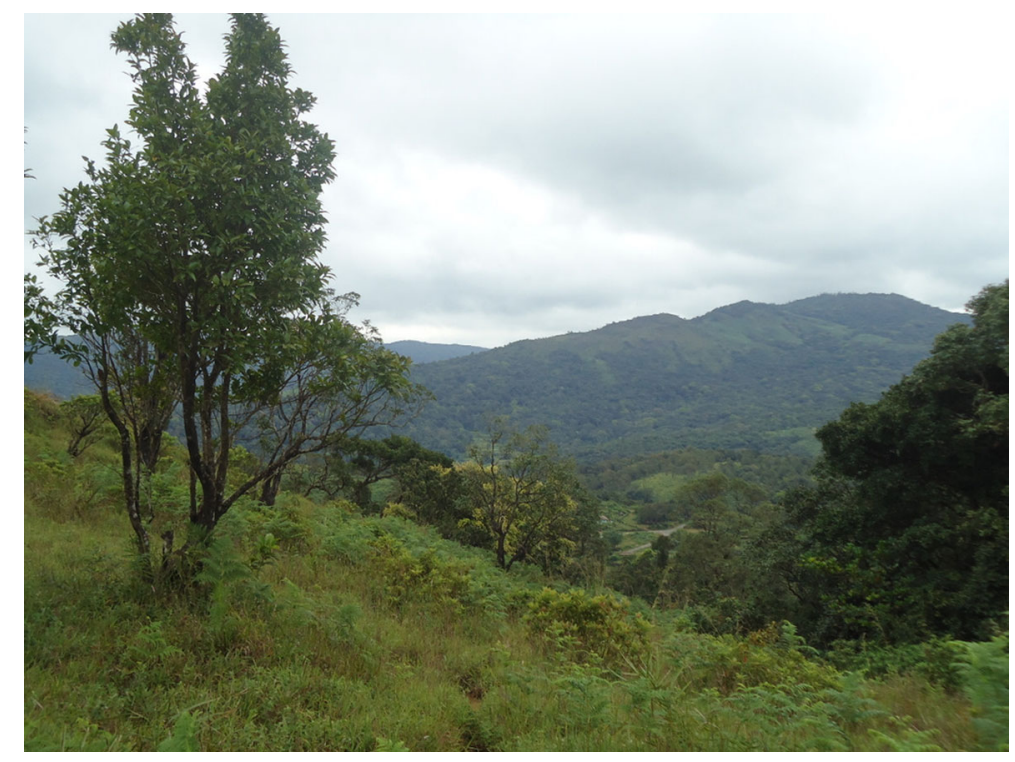

Plate 2. Typical landscape of the area, in the mid-altitudes, through which the garland canal passes.

during rainfall. The soil thickness in the region varies from about a meter in the grassed open land to more than $15 \mathrm{~m}$ on forested slopes.

The area through which the canal passes experiences very heavy rainfall, the normal annual magnitudes ranging between 3000 and $6000 \mathrm{~mm}$, throughout the length of the canal. However, rainfall during the southwest monsoon, which supplies more than $90 \%$ of the amount, is of the orographic type, characterized by low intensity falls lasting 20 to 22 hours on days of heavy rain (Putty et al. 2000). As a result, surface runoff on the slopes is restricted to very small areas near the crests of the hills and the runoff processes in the region are well explained by the Jones' theory of variable source volumes (Jones 1979; Putty and Prasad 2000). Accordingly, variable source area surface flow generated from saturated areas riparian to the stream (Hewlett and Nutter 1970), quick pipe flow from the upper layers of the soil mantle, and the slow ground water flow from the saturated subsurface zones form the predominant runoff components in the stream. The present study is carried out in the background of a field knowledge of these facts, with the intention of estimating the runoff available on the slopes as sheet flow and to understand the means by which the required quantity of water can be intercepted by garland canals.

\section{Methodology and the data used}

The present work consists of mainly two parts: (i) map analysis for marking the canal alignment and delineation of catchment characteristics, and (ii) estimation of surface runoff using data on rainfall and infiltration. The first part of the work has been carried out using the facility of GIS and information available on the 1:50,000 toposheets of the Survey of India. Since the rainfall data available is limited to that of normal annual rainfall and data on short duration magnitudes are not available, an innovative methodology has been devised in the present study to disaggregate the normal annual rainfall magnitude into 15-min amounts, which would be useful in estimating surface runoff. The data on infiltration rates have been obtained by measurements on the field, augmented by information furnished by previous studies in the region.

\subsection{Estimation of surface runoff}

Figure 3 shows the alignment of the study stretch of the canal, the drainage area intercepted by it, and other details, delineated from the toposheets. The $70 \mathrm{~km}$ of the stretch of the canal chosen for the study starts at an elevation of $812.00 \mathrm{~m}$ and ends near $800.00 \mathrm{~m}$, with a longitudinal gradient of approximately 1:6000. As seen from the map, the canal is located very near the ridge line throughout its length. It intercepts a very steep terrain with slopes up to IV:0.5H, in many parts, while in a few small stretches it lies in the flatter valley portions. The extent of the catchment area above the canal totals to $120 \mathrm{~km}^{2}$. Two types of land, with different vegetation covers, can be delineated on the slopes in this area: (i) thickly wooded and (ii) grassed. The relatively flat valley floors are usually cultivated with paddy and remain saturated throughout the rainy season. Experience shows that thickly wooded slopes, either with forests or 


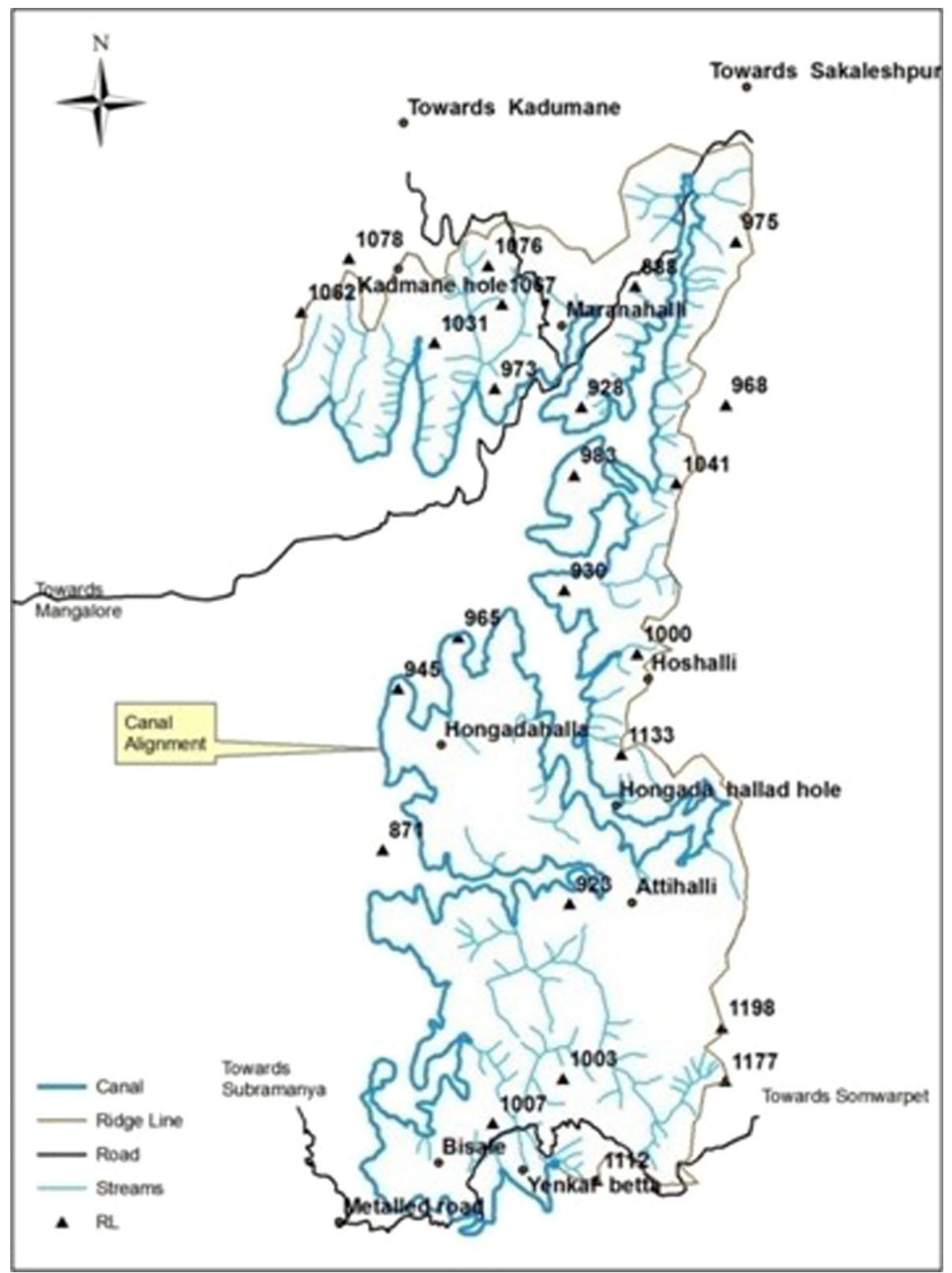

Figure 3. The alignment, the area drained and other details.

with cardamom and coffee plantations, do not permit any sort of flow on the surface since the equilibrium infiltration capacities (Chow et al. 1988) on them are of the order $30-120 \mathrm{~cm} / \mathrm{h}$ (Putty et al. 1997) and that small parts of grassed slopes (usually called 'grassy blanks') do often generate sheet flow. This flow, generally termed Hortonian runoff (Ward 1984), which gets generated when the rainfall intensity is greater than the infiltration rate, can be simulated by the expression

$$
\mathrm{ro}=(\mathrm{rf}-\mathrm{f})
$$

where the quantities ro (runoff), rf (rainfall) and f (infiltration) are instantaneous rates, expressed in terms of depth per unit time. Hence, the total runoff from an area can be obtained by integrating the instantaneous values of runoff over time. However, rainfall being a highly random variable, rf cannot be represented by a function and hence, integration can only be carried out by breaking down time into small intervals of approximately uniform intensities and summing runoff over the complete duration. In the present case, the intervals are considered to be of 15 -min each, since it has been a practice in India to use Self Recording Rain Gauge charts with this resolution.

\subsection{Infiltration rates}

Since it rains almost continuously during the monsoon in the study area, the soil remains always 
wet and the infiltration rates are seldom greater than the equilibrium rates. Hence, the surface runoff estimated is based on such rates and can be expected to be optimistic values - resulting in overestimation of runoff. Experimental studies on the field indicate that infiltration rates in the region are very high. Table 1 shows the ranges of equilibrium infiltration capacity commonly found in the region. This table has been prepared based on the results from the Double ring tests carried out in about 50 sites in the region. These tests include the 20 which were conducted for the purpose of the present study (Srinivasa et al. 2011) near the initial stretches of the canal proposed by Paramasivaiya (2000). The other tests, conducted in a nearby region have earlier been reported (Putty et al. 1997). It is evident from the table that absolutely no runoff can take place from forested slopes and that the infiltration rates on the grassed slopes, where surface runoff would occur during intense rains, vary between 20 and $60 \mathrm{~mm} / \mathrm{h}$. In order to estimate runoff from the grassed slopes, it is assumed in the present study that the spatial variation in the infiltration rates is uniform - all values in the range mentioned are supposed to have an equal chance of being found in the area. In order to facilitate the computations, the complete area of grassy blanks is divided into seven parts of equal areal extent and the value of infiltration capacity within these parts is expected to vary over ranges shown in table 2. For each of these seven parts, runoff is estimated using equation (1), assuming that the infiltration rate is equal to the lower limit of the respective range of values listed in this table. Further, runoff from saturated source areas riparian to the streams (Chow et al. 1988; Putty 2010) is considered equal to the rainfall amount, since no infiltration takes place on such surfaces.

\subsection{Rainfall intensity}

Since the region being studied forms interior areas of the Western Ghats, rainfall data available is limited. Only the normal annual rainfall for a few stations is known, which is the kind of data based on which yield estimation has been carried out by Paramasivaiya (2000). But, estimation of runoff from equation (1) requires intensity values. Hence, a methodology has been devised in the present study to generate 15-min intensity values from the known annual rainfall, based on analysis of records from self recording gauges available in the region. Incorporating intensity into long duration rainfall values has been attempted by many other investigators also. While some attempt to disaggregate daily rainfall into storms that resemble the natural rainfall as closely as possible (Hershenhorn and Woolhiser 1987; De Lima and Grasman 1999; Gyasi-Agyei 1999), Merten et al. (2002) have adopted a method of grouping the disaggregated total monthly rainfall under various intensity classes and estimating the contribution of each class. The methodology used in the present study, to disaggregate normal annual rainfall into 15-min depths, is similar to the one used by Merten et al. (2002). It is based on the inferences drawn by Tipperudrappa (2009) in an exhaustive study on intensity of rainfall in the Western Ghat areas.

Two of the important and unique features of the rainfall regime in the region evident from the study carried out by Tipperudrappa (2009) are: (i) that the total annual rainfall in any station is a function of the number of 15-min intervals during which it rains there and (ii) that the distribution of the 15-min intensity over the duration of rainfall is almost similar throughout the region influenced by the orography of the Western Ghats. A couple of results from his studies, reproduced here in figures 4 and 5, are used in the present work to disintegrate annual rainfall into 15-min depths. Figure 4 shows the relation between total annual rainfall and the number of rainy intervals for the area, which can be used to estimate the number of rainfall intervals during a normal year for any station. Thez curves in figure 5 show the percentage contribution of falls exceeding various 15 -min intensities to the total rainfall in a year

Table 1. Ranges of equilibrium infiltration capacity $\left(f_{\mathrm{c}}\right)$ measured in the study area.

\begin{tabular}{lcccccc}
\hline \multirow{2}{*}{$\begin{array}{l}\text { Slope type } \\
\text { location }\end{array}$} & \multicolumn{3}{c}{ Grassy blanks } & & \multicolumn{2}{c}{ Forested/cardamom slopes } \\
\cline { 2 - 4 } & Ridges & Middle & Stream side & & Surface & Below ground level \\
\hline $\mathrm{f}_{\mathrm{c}}(\mathrm{cm} / \mathrm{hr})$ & $6-12$ & $10-20$ & $2-6$ & & $30-60$ & $20-30$ \\
\hline
\end{tabular}

Table 2. Assumed distribution of infiltration capacity during rains on the grassy blanks.

\begin{tabular}{lccccccc}
\hline Part no. & 1 & 2 & 3 & 4 & 5 & 6 & 7 \\
\hline $\mathrm{f}_{\mathrm{c}}(\mathrm{mm} / \mathrm{hr})$ & 0 & $0-20$ & $20-40$ & $40-60$ & $60-80$ & $80-100$ & $100-120$ \\
$\mathrm{f}_{\mathrm{c}}(\mathrm{mm} / 15 \mathrm{~min})$ & 0 & $0-5$ & $5-10$ & $10-15$ & $15-20$ & $20-25$ & $25-30$ \\
\hline
\end{tabular}


and the percentage time duration for which such intensities last, for the station of Agumbe, which is known to experience the most intense rainfall in the region. The data used for this study have been procured from records of self-recording rain gauges in the region, for those years for which records are complete. They have been made available by the Water Resources Department of Karnataka. In the present work, the relationship in figure 4 is used for estimating the number of rainy intervals during a normal rainfall year and the intensity-prevalence-contribution curves (figure 5), have been used to estimate 15 -min rainfall depths.
The procedure used is applied in steps as explained below:

(i) The range of all possible 15-min intensities in the region are grouped into five classes, as shown in table 3 . The percentage time for which rainfall under each of the five classes lasts and the contribution of such falls to total rainfall are obtained from figure 5 and the values are tabulated. In this table, the information gathered from data pertaining to two stations, covering a good range of annual rainfall, is presented. However, for further work,

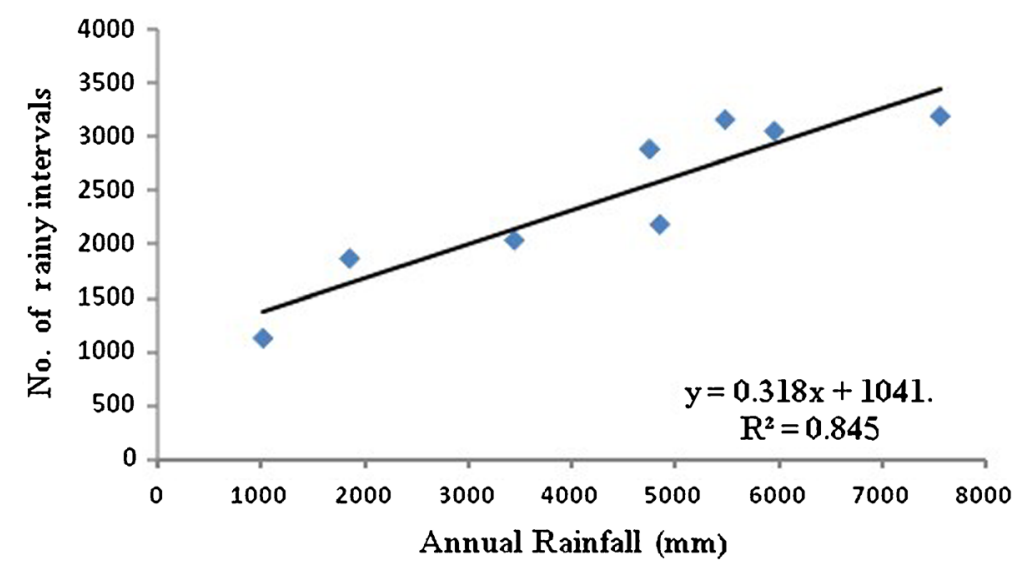

Figure 4. Relation between total annual rainfall and the number of rainy intervals.

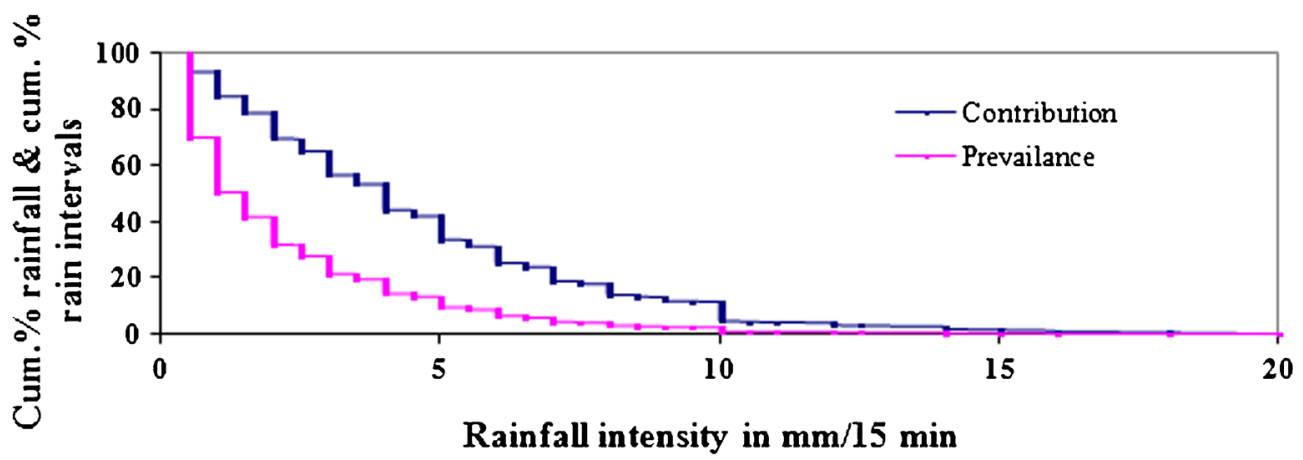

Figure 5. Percentage contribution of falls exceeding various 15-min intensities to the total rainfall in a year and the percentage time duration for which such intensities last.

Table 3. Rainfall contribution by falls exceeding various intensities and the duration for which they prevail.

\begin{tabular}{|c|c|c|c|c|c|c|c|c|c|c|c|}
\hline \multirow[b]{2}{*}{ Station } & \multirow{2}{*}{$\begin{array}{c}\text { Annual } \\
\text { rainfall } \\
(\mathrm{mm})\end{array}$} & \multicolumn{5}{|c|}{$\begin{array}{l}\text { Percentage contribution of rainfall by } \\
\text { falls exceeding intensities }(\mathrm{mm} / \mathrm{hr})\end{array}$} & \multicolumn{5}{|c|}{$\begin{array}{c}\text { Percentage of } 15 \text {-min intervals in } \\
\text { which intensities exceeded }(\mathrm{mm} / \mathrm{hr})\end{array}$} \\
\hline & & 24 & 32 & 40 & 60 & 80 & 24 & 32 & 40 & 60 & 80 \\
\hline \multirow[t]{3}{*}{ Agumbe } & 7558 & 41.00 & 28.00 & 19.20 & 6.20 & 2.00 & 10.80 & 6.00 & 3.80 & 1.30 & 1.00 \\
\hline & 5960 & 23.30 & 11.80 & 2.40 & 1.20 & 0.00 & 5.40 & 2.30 & 0.30 & 0.10 & 0.00 \\
\hline & 4853 & 25.30 & 13.90 & 4.60 & 1.40 & 0.00 & 6.40 & 2.80 & 0.70 & 0.20 & 0.00 \\
\hline \multirow[t]{2}{*}{ Bhagamandala } & 4758 & 24.80 & 13.40 & 8.30 & 1.80 & 1.30 & 5.00 & 2.00 & 1.20 & 0.10 & 0.07 \\
\hline & 5485 & 34.00 & 22.00 & 12.90 & 4.50 & 2.20 & 6.80 & 3.60 & 1.80 & 0.60 & 0.40 \\
\hline
\end{tabular}


the set resulting in the most optimistic values of runoff is chosen.

(ii) Based on the data of normal annual rainfall, the number of rainy intervals and the contribution of rainfall corresponding to each of the intensity classes are estimated, for the stations in the catchment draining to the canal. In the present work, data from five stations (figure 7, table 3) in the vicinity of the canal, whose normal annual rainfall values are furnished by the Karnataka Power Corporation Limited, are used.

(iii) The total amount of rainfall within each class interval is now distributed to the estimated number of intervals assuming that 'all possible values of intensity have an approximately equal chance of being present'. The method is illustrated in figure 6 . Here, the continuous range of intensity variation is broken into discrete events, grouped into a few classes and each class assigned an intensity value such that total rainfall is equal to that estimated empirically in step (ii) above. Hence, for the case shown in the figure, $\sum i_{j} n_{j}$ is equal to the

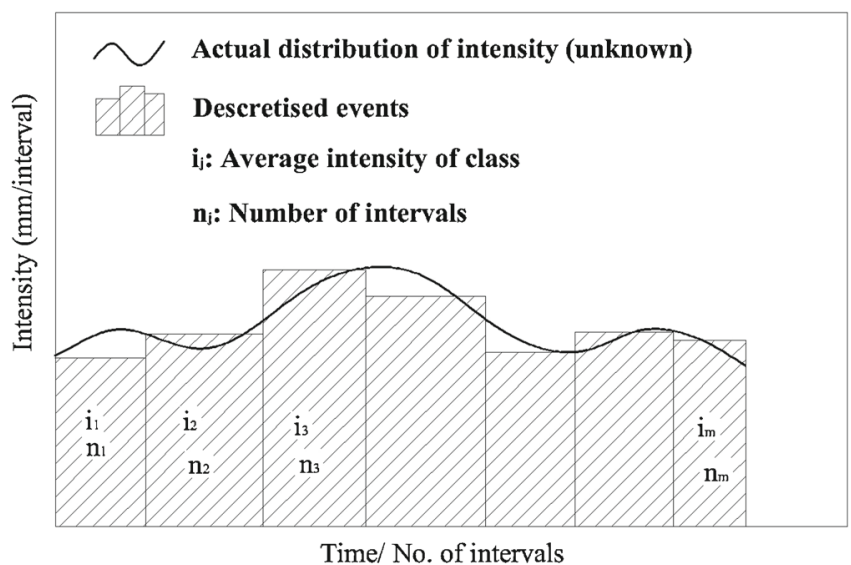

Figure 6. Splitting the continuous rainfall (with an unknown intensity pattern) into discrete events. total rainfall in the class. Two examples are furnished below:

\section{1) Station: Kadumane}

Annual rainfall: $5231 \mathrm{~mm}$,

Intensity range: $10-15 \mathrm{~mm} / 15$ minutes.

Number of 15-minute intervals: 10, total rainfall for the class: $116 \mathrm{~mm}$ (obtained using table 3). Suggested pattern of distribution: Falls of 10.5, 11, 11.5, 12 and $13 \mathrm{~mm}$, each two numbers.

2) Station : Attihalli

Annual rainfall: $5351 \mathrm{~mm}$,

Intensity range : $6-8 \mathrm{~mm} / 15$ minutes.

Number of rainfall intervals: 90; total rainfall for the class: $612 \mathrm{~mm}$ (obtained using table 3 ).

Suggested pattern of distribution : Falls of 6.2 , 6.5, 6.8, 7.0 and $7.5 \mathrm{~mm}$, each 18 numbers.

It may be noted that this method of converting continuous rainfall into discrete events is purely arbitrary. Yet, it is rationally based and is applied within small ranges of intensity, the contribution of which to total rainfall is estimated empirically. The method serves the purpose of obtaining a dataset of 15-min rainfall depths for the normal rainfall year. This dataset would help in estimating surface runoff that is expected to be collected and diverted by the canal.

\subsection{Surface runoff yield}

Surface runoff from each of the seven parts of the grassy blanks is estimated using equation (1), as illustrated in table 4 for one of the intensity ranges. Runoff values so estimated separately for each of the intensity ranges are summed up. Then, since it is assumed that the seven parts of the grassy blanks occupy equal extents of area, the yield from this type of land can be obtained as the product of the area and the average runoff. Yield from saturated source areas riparian to the streams is estimated as equal to the product of rainfall depth and the

Table 4. Estimation of surface runoff from the grassy blanks, an example. Station : Kadumane; Intensity range: $10-15 \mathrm{~mm} / 15 \mathrm{~min}$.

\begin{tabular}{ccrrrrrrr}
\hline & & \multicolumn{3}{c}{$\begin{array}{c}\text { Runoff* in } 15 \text { min due to } \\
\text { rainfall of }(\mathrm{mm} \text { in } 15 \mathrm{~min})\end{array}$} & $\begin{array}{c}\text { Runoff }(\mathrm{mm}) \\
\text { in one }\end{array}$ & $\begin{array}{c}\text { Runoff (mm) } \\
\text { in two }\end{array}$ \\
\cline { 2 - 7 } 1 & 0 & 10.5 & 11 & 11.5 & 12 & 13 & 58 & 116 \\
2 & $0-5$ & 10.5 & 11 & 11.5 & 12 & 13 & 58 & 116 \\
3 & $5-10$ & 5.5 & 6 & 6.5 & 7 & 8 & 33 & 66 \\
4 & $10-15$ & 0.5 & 1.0 & 1.5 & 2.5 & 3 & 17 & 34 \\
5 & $15-20$ & 0 & 0 & 0 & 0 & 0 & 0 & 0 \\
6 & $20-25$ & 0 & 0 & 0 & 0 & 0 & 0 & 0 \\
7 & $25-30$ & 0 & 0 & 0 & 0 & 0 & 0 & 0 \\
\hline
\end{tabular}

${ }^{*}$ Runoff estimated (as equal to rainfall - minimum value of $f_{c}$ ) is an optimistic value. 
area. Obviously, Horton's runoff from the forested areas is zero. Using these approaches, runoff yield from each of the Thiessen areas corresponding to the five stations selected is estimated separately. The results are presented and discussed below.

\section{Results and discussion}

The typical landscape of the area through which the garland canal passes is shown in Plates 1 and 2 . The canal, located in a highly mountainous terrain, intercepts a large number of streams. In the study length of $70 \mathrm{~km}$, it intercepts more than 100 first order streams and 30 higher order streams. Hence, the land area in the catchment above the garland canal can be divided into two parts: the first area draining into the canal, sheet flow which reaches the canal before entering the stream, and the other draining water directly into the streams. It may be noted that in order to collect surface runoff draining into the streams, the canal alignment will have to be taken curving round the contour along the border of each of the valleys or else, elaborate arrangements, consisting of a weir and a diversion canal, will have to be provided. It is assumed in the present case that the flow in all first order streams can be collected by the canal directly and that the flow into the higher order streams is not tapped at all. Figure 7 shows the distribution of the two types of the drainage area upstream of the canal. The distribution of the land cover over the catchment is presented in

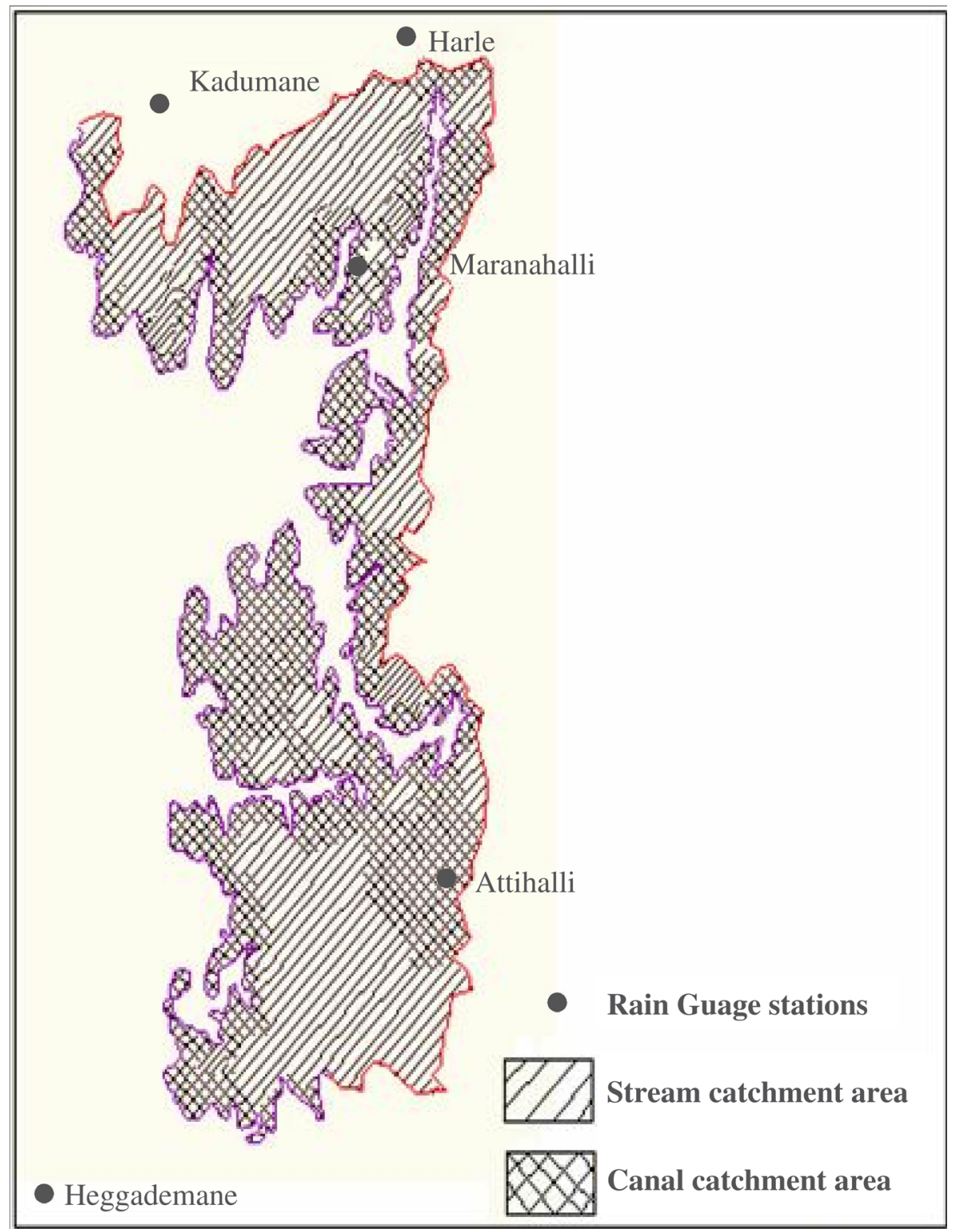

Figure 7. Location of the rain gauges and the two parts of the catchment draining respectively into the canal and the streams. 
figure 8. Table 5 shows the details concerning extent of the land under various parts of catchment. The quantity of runoff yield available from these parts, corresponding to a normal rainfall year, estimated using the procedure outlined in the last section, is presented in table 6 .

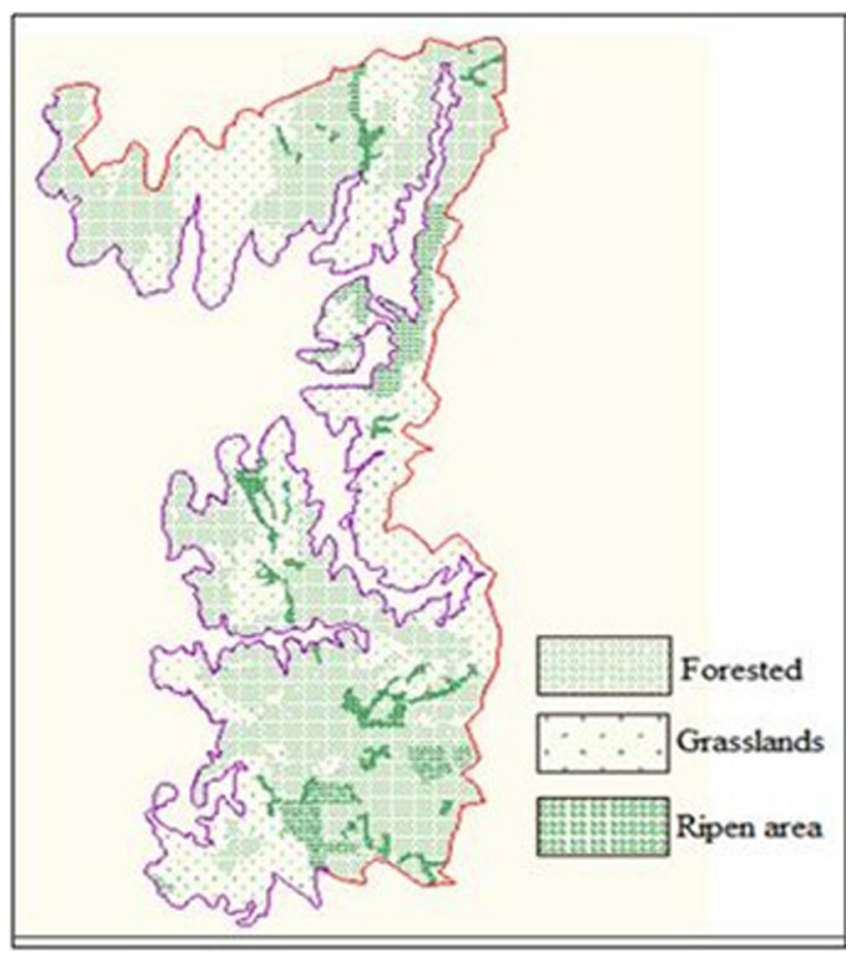

Figure 8. The different land cover types over the catchment.
As evident from the figures in table 6, the amount of sheet flow draining directly into the canal, including that from the first order streams and the saturated source areas, is $48 \mathrm{Mm}^{3}$. Even if it is assumed that sheet flow into all the streams is also diverted into the canal, the total volume available during a normal rainfall year is about $90 \mathrm{Mm}^{3}$, in a length of $70 \mathrm{~km}$ of the garland canal. If it is assumed that the hydrology of the complete $234 \mathrm{~km}$ length of the canal is similar to that in this $70 \mathrm{~km}$ study stretch, the volume of surface runoff that can be intercepted by the said canal is about $300 \mathrm{Mm}^{3}$ (10.5 TMC), while that expected by Paramasivaiya (2000) is in the order of $1245 \mathrm{Mm}^{3}$ (44 TMC). The value of the yield estimated by Paramasivaiya (2000), (it is understood through personal communications with him (Badarinath et al. 2010)), is based on the notion that Hortonian infiltration excess surface runoff occurs on extensive areas in the region and that during the monsoon, when it rains heavily, the infiltration capacities are negligibly low. The present study has shown that such assumptions are not justified in the Western Ghat areas.

As is well known now (Ward and Robinson 2011), subsurface flow, either through the soil matrix or through pipes, is the dominant runoff process contributing flow to streams in mountainous and forested head water areas. High values of infiltration result in excessive watershed storage and subsequent subsurface flow. Subsurface runoff leads to flow directly into the stream and as a

Table 5. Details concerning the extent of land under the various parts of the catchment.

\begin{tabular}{|c|c|c|c|c|c|c|}
\hline \multirow[b]{3}{*}{ Station } & \multicolumn{6}{|c|}{ Catchment area in $\mathrm{km}^{2}$} \\
\hline & \multicolumn{3}{|c|}{ Stream catchment area } & \multicolumn{3}{|c|}{ Canal catchment area } \\
\hline & Grasslands & Forests & Riparian Area & Grasslands & Forests & Riparian area \\
\hline Heggademane & 0.59 & 0.01 & 0.17 & 2.93 & 0.00 & 0.07 \\
\hline Attihalli & 10.18 & 15.18 & 3.01 & 9.19 & 16.01 & 4.11 \\
\hline Maranahalli & 12.18 & 1.30 & 0.81 & 12.74 & 9.66 & 0.93 \\
\hline Harle & 1.31 & 0.00 & 0.24 & 1.77 & 0.04 & 0.00 \\
\hline Kadumane & 1.41 & 4.19 & 0.00 & 2.01 & 9.92 & 0.00 \\
\hline
\end{tabular}

Table 6. Runoff yield from different parts of the catchment.

\begin{tabular}{|c|c|c|c|c|c|c|}
\hline \multirow[b]{2}{*}{ Station } & \multirow{2}{*}{$\begin{array}{l}\text { Annual } \\
\text { rainfall } \\
(\mathrm{mm})\end{array}$} & \multirow{2}{*}{$\begin{array}{l}\text { Runoff from } \\
\text { Grassy } \\
\text { blanks (mm) }\end{array}$} & \multicolumn{2}{|c|}{ Yeild $\left(\mathrm{Mm}^{3}\right)$ from } & \multirow{2}{*}{$\begin{array}{c}\text { Total } \\
\text { yield } \\
\left(\mathrm{mm}^{3}\right)\end{array}$} & \multirow{2}{*}{$\begin{array}{l}\text { Total } \\
\text { yield } \\
(\mathrm{TMC})\end{array}$} \\
\hline & & & $\begin{array}{c}\text { Stream } \\
\text { catchment }\end{array}$ & $\begin{array}{c}\text { Canal } \\
\text { catchment }\end{array}$ & & \\
\hline Heggademane & 6120 & 951.4 & 1.7 & 3.1 & 4.8 & 0.17 \\
\hline Attihalli & 5351 & 855.8 & 24.6 & 29.7 & 54.4 & 1.92 \\
\hline Maranahalli & 4369 & 687.6 & 11.9 & 12.7 & 24.6 & 0.87 \\
\hline Harle & 3360 & 567.6 & 1.4 & 1.1 & 2.6 & 0.09 \\
\hline Kadumane & 5231 & 839.6 & 0.13 & 1.7 & 1.8 & 0.06 \\
\hline Total & & & 39.73 & 48.3 & 88.2 & 3.11 \\
\hline
\end{tabular}




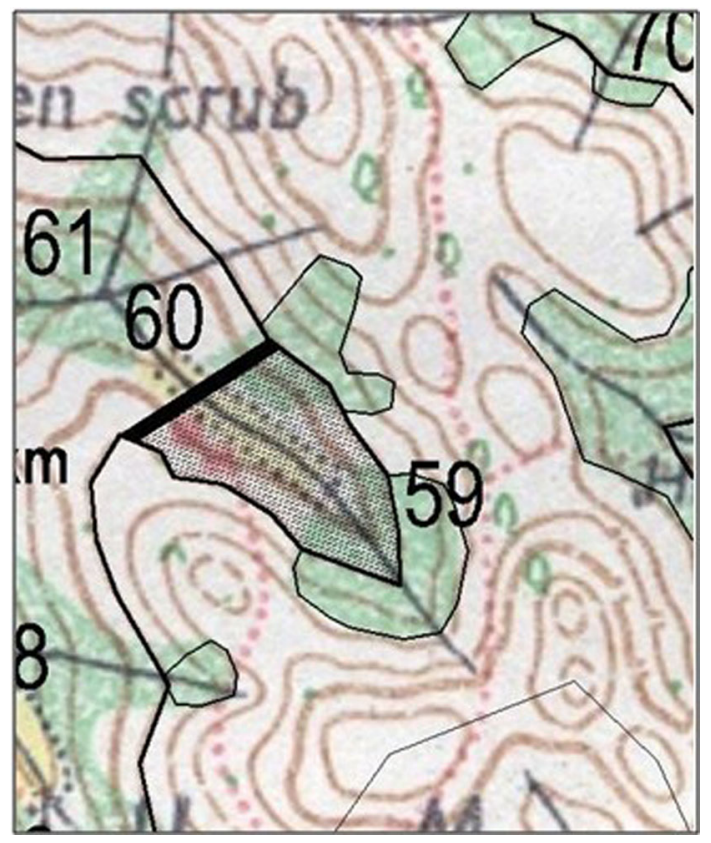

Figure 9. Arrangements necessary to divert flow in a stream - the nearly $40 \mathrm{~m}$ high weir across a first order stream (stream no. 59) in this case reduces the canal length by 0.68 $\mathrm{km}$, but submerges about 7.5 ha of the valley.

result, trenches cut on the surface cannot intercept this component of stream flow. Hence, it is apparent that garland canals do not serve the purpose unless they are designed to tap the part of stream flow contributed by subsurface runoff also, which empties into the stream, often, far below (downstream of) the point of infiltration. It becomes necessary to make elaborate arrangements to tap this water in the garland canal.

The arrangements required to tap flow in a stream is shown in figure 9. Even in case of a first order stream like the one shown, which reduces the canal length by about $75 \%$, the dam height is more than $20 \mathrm{~m}$ and the submersion is about 8 ha. Hence, tapping subsurface flow means innumerable dams and a large submersion. In fact, submersion due to multiple dams replacing a single dam is always more (Prasad and Malhotra 1987) and hence, they may not be feasible at all.

\section{Summary and conclusions}

It is often believed that in the heavy rainfall areas of the Western Ghats, the surface runoff is widespread since daily rainfall intensities are very high and the infiltration rates are always low on very wet surfaces. The present study was taken up to estimate the runoff yield that may be collected in canals constructed so as to intercept slopes on which surface runoff is believed to occur, for the purpose of diverting west flowing rivers to the east by gravity. Investigations have been carried out on a stretch of $70 \mathrm{~km}$ of the $234 \mathrm{~km}$ garland canal proposed for diverting the flow from Netravathi. The amount of surface runoff that can be collected in the canal has been estimated by disaggregating normal annual rainfall magnitudes into 15-min depths and deducting the infiltration rates that commonly prevail in the region. The inferences drawn from the study can be summarized as below:

- rainfall intensities in the region being only moderate, despite very high annual totals, surface runoff even on the grassed slopes amounts to not more than $15 \%$ of the rainfall;

- since garland canals, on their own, cannot intercept the complete amount of surface runoff that may occur, additional arrangements will have to be made to tap sheet flow which would otherwise feed the streams directly;

- yield from surface runoff, even if the complete amount is tapped, amounts to just about $25 \%$ of the volume proposed to be diverted by the canal investigated;

- arrangements necessary to tap stream flow contributed by subsurface processes lead to submersion of vast areas of Shola forests, which host rich biodiversity.

In view of these findings, it should be concluded that garland canals that are being claimed to be a safer alternative to the conventional means, consisting of reservoirs and pumping, for diverting west flowing rivers, may not be hydrologically feasible.

\section{Acknowledgements}

This study is a part of the research project 'Impact of LULC Changes on Stream flow Regime - A case study of Netravathi Catchment, Karnataka', sponsored by ISRO, under its RESPOND Programme. The authors acknowledge with gratitude the financial assistance provided for the project by ISRO. The authors also acknowledge the students of The National Institute of Engg., Mysore, who are involved in the studies concerning the project.

\section{References}

Badarinath B, Muralidhar S, Waddatti S H and Kulakarni V S 2010 A study on diversion of water in Netravathi basin by garland canals; Unpubl. BE dissertation submitted to NIE, Mysore.

Chow V T, Maidment D R and Mays L W 1988 Applied Hydrology; McGraw-Hill Book Co., New York.

De Lima M I P and Grasman J 1999 Multifractal analysis of 15 -min and daily rainfall from a semi-arid region in Portugal; J. Hydrol. 220 1-11. 
Gyasi-Agyei Y 1999 Identification of regional parameters of a stochastic model for rainfall disaggregation; J. Hydrol. 223 148-163.

Hershenhorn J and Woolhiser D A 1987 Disaggregation of daily rainfall; J. Hydrol. 95 299-322.

Hewlett J D and Nutter L W 1970 The varying source area of stream flow from upland basins; Proc. Symp. Watershed Management August 70, Montana State Univ., Bozeman, Montana Publ., ASCE NY, 10017 65-83.

Jones J A 1979 Extending the Hewlette model of stream runoff generation area; Inst. of British Geographers 112 110-114.

Merten J, Raes D and Feyen J 2002 Incorporating rainfall intensity into daily rainfall records for simulating runoff and infiltration into soil profiles; Hydrol. Process. 16 731-739.

Paramasivaiya G S 2000 'Project at a glance' - report on gravity diversion of Netravathi submitted to Govt. of Karnataka on $25 / 08 / 2000$.

Prasad R and Malhotra K 1987 Some aspects of water resources in Karnataka; Published by Dept. of Civil Engg., Indian Institute of Science, Bengaluru.

Putty M R Y 2010 Principles of Hydrology; IK International Publ., New Delhi.
Putty M R Y and Prasad R 2000 Runoff processes in head water catchments - an experimental study in Western Ghats, south India; J. Hydrol. 235 63-71.

Putty M R Y, Prasad V S R K and Ramaswamy R 2000 A study on the rainfall intensity pattern in Western Ghats, Karnataka; Proc. Workshop on Watershed level in Western Ghats, CWRDM, Kozhikode, Kerala, February 2000, pp. 44-51.

Putty M R Y, Swamy B K K and Prasad R 1997 A study on infiltration rates in a very wet zone of the Western Ghats; Hydrol. J. IAH 20(1-4) 1-17.

Srinivasa P, Anil Kumar H V, Santhosh R and Avinash A 2011 Infiltration rate studies at the Kumaradhara Basin of Western Ghats; BE project report submitted to the Department of Civil Engineering, The National Institute of Engineering, Mysore.

Ward R C 1984 On the response of headwater streams in humid areas; J. Hydrol. 74 171-189.

Ward R C and Robinson M 2011 Principles of Hydrology, 4th edn; Tata McGrawHill, New Delhi.

Tipperudrappa N M 2009 Studies on rainfall intensity pattern in Karnataka with particular reference to the Western Ghats; Unpubl. Ph.D. thesis submitted to Visvesvaraya Technological University, Belgaum, Karnataka, India. 